\title{
Moral Progress: an Introduction
}

\author{
Albert W. Musschenga ${ }^{1} \cdot$ Gerben Meynen ${ }^{1}$
}

Accepted: 16 January 2017 / Published online: 3 February 2017

(C) Springer Science+Business Media Dordrecht 2017

This special issue contains 11 articles that are revisions of keynote lectures and papers that were presented during the conference 'Moral Progress: Concepts, Measurements, and Applications' that took place on June 24-25, 2015 at the Vrije Universiteit, Amsterdam. Ethical Theory and Moral Practice was one of the sponsors. This introduction explores the issue of moral progress, analyses relevant recent publications, and situates as well as summarises the other contributions to the special issue.

\section{Conceptual Issues}

Is our world today a morally better place to live in than, say, the world a century ago? How can we make the world a morally better place? The first question demands a comparative evaluation of two states of affairs while the second question asks for a strategy of social action. Both questions are discussed in recent literature on moral progress and in various contributions to this issue; both require that we know what progress is and, more specifically, what moral progress is.

Progress is different from mere change. A patient cannot be said to make progress in restoring health just because he regains weight. A change can only be called progress when a subsequent state is overall better than a preceding one (Jamieson 2002b, p. 318). ${ }^{1}$ Moreover, there should be causal links between the subsequent and the preceding state. An architect cannot be said to have made progress in designing a house if he randomly made some changes which only by chance resulted in a better design. Conceiving of progress as a process of change also suggests that it consists of an ongoing series of changes in which not all the

\footnotetext{
${ }^{1}$ This is only the first part of Jamieson's definition. His definition also includes an alternative: 'or when right acts become increasingly prevalent'. We regard that as a criterion of moral progress rather than a (part of a) definition.
}

Albert W. Musschenga

a.w.musschenga@vu.nl

Gerben Meynen

g.meynen@vu.nl

1 Department of Philosophy, Vrije Universiteit, De Boelelaan 1105, 1081 HV Amsterdam, Netherlands 
subsequent states need to be better than the preceding ones. What matters is that the end state is better than the state at the beginning. Progress can be understood either as a teleological or culminative process - as a process with a culminating or completion state that may also involve strict or orderly succession where change passes through a set of sequences in a programme or progression - or as a process of improvement, an ameliorative process, a 'change for the better' (Godlovitch 1998, p. 273). Some thinkers regard liberal democracy as the end stage of the development of the state, while other authors regard it as just an improvement to the authoritarian state. In both cases progressive processes can be infinite. Of note, the telos of a teleological process may only be approximated but never be reached. An athlete can continuously improve his performance without there being a perfect performance that cannot be improved any more.

In previous centuries, progress was usually understood as a process of civilisation. ${ }^{2}$ The term 'civilisation' has become obsolete nowadays. It is now suspect to say that 'we' are more civilised than people with a less complex culture or than our ancestors. While the term 'civilisation' refers to the level of development of a society in its entirety, it is nowadays more common to relate progress to specific domains, for example, technology, economy, medicine, or politics. We call progress partial if it takes place in one or only a few domains of society. If progress takes place in all, or at least most, of the domains, we call it comprehensive. It was assumed in the past that civilisation would spread itself over the entire world. Progress was thought to be a global process that knew of different stages. Some nations and cultures were more advanced than others because the speed of development was, due to internal or external factors, not everywhere the same. ${ }^{3}$ Nowadays, even those who claim that there is progress are hesitant to believe that progress will be global. They believe that progress might only occur in some parts of the world, and not in others. For them, progress is always local.

Although many people agree that there has been, and still is, progress in, for example, the economic and the technological domain, progress in these domains need not imply moral progress. ${ }^{4}$ What, then, is moral progress? There are two families of definitions of morality. Some authors conceive morality narrowly, others conceive it broadly. In the narrow conception morality refers to values, principles and rules that constrain an individual in realising his conception of the good life. Narrow morality is other-regarding. It protects the interests and the well-being of sentient beings other than the actor. In the broad conception morality comprehends the values, principles and rules that guide an actor in forming and realising a conception of the good life. Most authors use the term 'moral' in the narrow sense and conceive moral progress as a process of amelioration of the way we deal with other living beings, including other human beings. The distinctions we made above with regard to progress can also be applied to moral progress: between comprehensive and partial moral progress, and between global and local moral progress.

\footnotetext{
${ }^{2}$ See John Beattie Crozier, Civilization and Progress (1898)

${ }^{3}$ August Comte, e.g., believed that society went through different stages of development, culminating in the stage of positivism based upon scientific analysis (Comte 1830-1842).

${ }^{4}$ Ruth Macklin, e.g., states: 'We need to guard against several errors that might arise out of this account of the notion of progress. First, even if a judgment is correctly made that progress has occurred in a particular sphere, say, in the area of technology, it does not follow that the changes constituting this progress are good for mankind as a whole. That is, progress in a particular area of human activity may properly be judged as progress according to the appropriate criteria for that area, without implying that such progress is, on the whole, good for mankind' (Macklin 1977, p. 373).
} 
At present, our conceptual apparatus does not appear sophisticated enough to answer the question of whether there is moral progress. We still have to find out who or what is making moral progress. Who or what is the primary subject or the bearer of moral progress? Is it the individual or the collective - a group, a society, a nation, or humanity as a whole? Or is the structure and the institutions of the collective?. Since morality is built of different components, the subsequent question is in which component or components progressive changes can be observed: which is the locus or are the loci of moral change. We distinguish four components of the morality system ${ }^{5}$ :

1. the cognitive component: moral values, principles, rules, judgements - 'the moral code';

2. the affective component: motivations and emotions from which people act;

3. the behavioural component: actions and habits

4. the supra-individual component: the structure and institutions in which a collective's morality is deposited.

We assume that morality's components are interdependent, implying that if moral progress occurs, all components will undergo changes. Moral progress is likely to lead to positive changes in the content of moral beliefs, in the moral quality of motivations, in the correspondence between beliefs and behaviour, as well as in the structure and institutions of society. Depending on their theoretical moral preferences, scholars investigating moral progress may regard one component as the prime locus of moral progress that causes changes in the other components.

\section{Criteria for Moral Progress}

To know whether society A has undergone progressive moral changes in the last half a century, we need criteria to determine if the current state of affairs is indeed morally better than that of half a century ago. We distinguish between different kinds of criteria: formal, epistemic, quantitative, qualitative, functional and substantive criteria. Most, but not all of these criteria can be found in recent literature on moral progress.

\subsection{Epistemic Criteria}

Within scientific realism, scientific theories are regarded as attempts to describe reality, and scientific statements as having truth-value. Progress occurs when theories become more successful in describing reality and when the statements derived from these theories have a higher truth value. Theories should be testable by observational evidence, and increasing success in empirical tests means a higher degree of confirmation of a theory. Some moral philosophers attempt to model progress in morality on progress in science, and conceive moral progress as greater success in describing moral reality (Boyd 1988). They find that it is impossible to speak of moral progress without accepting that there is a moral reality. For them, moral progress presupposes moral realism. Moral philosophers who do not believe in

\footnotetext{
${ }_{5}^{5}$ Philosophers usually focus on the cognitive component of morality, 'the moral code', psychologists on the behavioural and affective components, and sociologists on the supra-individual component. The term 'morality system' is meant to cover all components. We derive the term 'component of morality' from James Rest (1986).
} 
there being a moral reality reject the notion that one cannot talk about moral progress without being committed to moral realism. Catherine Wilson wants to hold onto the analogy between moral progress and scientific progress but argues that a viable notion of moral truth is better elicited from the dynamics of theory change than from the metaphysics of propositional content (Wilson 2010, p. 98). Wilson's account of moral progress is criticised by Michael Huemer, who argues that certain empirically observable positive moral changes in the preceding centuries cannot be explained by theories that debunk moral realism (Huemer 2016). Dale Jamieson rejects moral realism, because it violates our metaphysical sensibilities (Jamieson 2002 b, p. 321). He proposes to replace the account of morality mirroring an external reality by an evolutionary account that should be understood as explaining why morality evolved and persists among creatures like us (p. 322). Those who look for a workable epistemic criterion for moral progress will not find anything usable in the discussion on moral progress and its relation to moral realism. That discussion is focussed on what is required for explaining moral progress, not on tools for determining moral progress.

An alternative epistemic interpretation of moral progress is given by Michelle MoodyAdams. For her, moral progress in beliefs consists of grasping the semantic depth of moral concepts which involves coming to understand more fully the richness and range of a moral concept. Moral progress in practices results when some newly deepened moral understanding is concretely realized in individual behavior or social institutions (Moody-Adams 1999, p. 169). This criterion might lend itself for operationalisation when the notion of semantic depth is more fully elaborated.

\subsection{Formal Criteria}

One of the most accepted images of moral progress is that of an expanding circle of moral concern, beginning with our own family or tribe, and expanding over time to include larger groups, nations, families of nations, all humans and perhaps even nonhuman animals. This metaphor, already present in William E.H. Lecky's History of European Morals (1809), is central to Peter Singer's The Expanding Circle (1981), and taken over by many other authors, for example, Dale Jamieson (2002a,b). Singer argues that altruism began as a genetically based drive to protect one's kin and community members but has developed into a consciously chosen ethic with an expanding circle of moral concern. ${ }^{6}$ Godlovitch (1998) adds to this criterion of the expansion of moral scope two other formal criteria: that of the increase of the moral domain and that of increasing moral dominance or authority:

Domain growth makes more choices and actions morally wrong by increasing the number of obligations we must accept. Authority growth makes existing moral obligations more stringent and leaves less room open for excusable, unreflective, self-serving customs and preferences. Moral progress requires that the sphere of uncontestably permissible conduct increasingly shrinks by making an ever-greater proportion of our actions to be 'matters of principle' (p. 279f).

The great advantage of formal criteria is that they are easily applicable. Moral progress has occurred wherever it can be observed that the scope of morality and/or its domain and/or its authority have increased.

\footnotetext{
${ }^{6}$ For Philip Kitcher's (2011) critique on the image of the expanding circle, see below.
} 


\subsection{Quantitative Criteria}

The formal criteria we just discussed are in a way also quantitative in that measuring the increase of the scope, domain and authority of morality requires - or is at least compatible with - a quantitative scale. A pure quantitative criterion is increase of right actions (Jamieson) or greater correspondence between moral beliefs and moral behaviour, which can also be seen as a sign of the greater dominance of morality. Quantitative criteria are easily applicable but cannot stand alone: they presuppose substantial criteria (see below).

\subsection{Qualitative Criteria}

In everyday life, actions are usually done from a mix of motives. Some of them are selfinterested, others are other-regarding and express concern for the weal and woe of others than the agent himself, still others are purely moral in the Kantian sense. According to Kant, actions only have moral worth if they are done solely from the motive of duty (Kant 2002). When moral progress is conceived as increasing purity of moral motivation, it is, at least in theory, possible to determine whether moral progress did occur. Yet, since moral motives are often opaque, even to the agents themselves, it is in practice almost impossible to find out whether there was moral progress. The criterion of increasing purity of motivation is therefore difficult to operationalise.

\subsection{Functional Criteria}

If we know what the function of morality is, it is, at least theoretically, possible to compare the degree to which moralities fulfil that function. ${ }^{7}$ Recently, Philip Kitcher (2011) developed a theory of moral progress based on a functional account of morality. ${ }^{8}$ At some point in our evolutionary past, Kitcher says, our ancestors acquired an ability to live together in small groups mixed in terms of age and sex. That achievement required a capacity for altruism. Altruism is exemplified in maternal concern and originally evolved through kin selection. Altruistic dispositions, however, are limited and fragile. Co-operators are sometimes exploited, returns are uneven. Defections threaten to tear the social fabric of the group. Kitcher speaks of 'altruism failures'. The limits and fragility of altruism do not threaten daily social life within a group, they prevent gathering in larger social groups and expansion of cooperation. To make that possible a device is required which Kitcher calls 'capacity for normative guidance', that is, the capacity to follow commands and rules. The capacity for normative guidance is a cognitive capacity. Normative guidance produces surrogates for altruism in animals who can follow orders. Its function is to remedy altruism failures. Various moral codes were developed within what Kitcher calls 'experiments of living':

\footnotetext{
$\overline{7}$ A well-known functional definition of human morality was given by G.J. Warnock (1971): ‘... the "general object" of morality, appreciation of which may enable us to understand the basis of moral evaluation, is to contribute to betterment — or non-deterioration — of the human predicament, primarily and essentially by seeking to countervail 'limited sympathies' and their potentially most damaging effects' (p. 26).

${ }^{8}$ As a pragmatic naturalist, Kitcher rejects claiming truth for moral beliefs, thus also epistemic criteria for establishing moral progress. It is enough to establish whether a morality $\mathrm{M}$ is objectively better than morality $\mathrm{M}^{*}$ : "To salvage the notion of "objectively better than" that occurs in these claims and counterclaims, we do not need any concept of ethical truth. It is enough to recognize which kinds of changes would be progressive or regressive.' (Kitcher 2011, p. 220).
} 
The experiments of living of our prehistoric ancestors generated an important mode of progress that fits the 'expanding circle' account, in extending their prescriptions beyond the small bands of the first human beings, as well as increasing the scope of (behavioral) altruism (Kitcher 2011, p. 217).

Many examples of moral progress are, according to Kitcher (2011, p. 236f.), functional refinements of the original function of moral codes, achieved by widening the scope of moral precepts. In the earlier phases of human history the altruism failures that moral codes had to remedy were related to social conflicts pertaining to the satisfaction of the basic desires of group members. In the course of the history of successful human coexistence and cooperation, new desires were formed. From the ways in which the original function of ethics was discharged, secondary functions are generated:

Ethical principles are also required to respond to conflicts within the individual's expanded repertoire of desires, and in this sphere, prescriptions for character development emerge (2011, p. 239).

Progress in fulfilling these secondary functions does not fit the expanding circle account, according to Kitcher.

The advantage of functional criteria seems to be that they are normatively neutral: they do not require an evaluative base - a set of moral beliefs, values, principles and rules on which judgements about moral progress are based. However, Kitcher argues that we can derive from the empirically discovered function of ethics nothing less than a normatively binding egalitarian ideal: an ideal of ethical deliberation that is sensitive to the desires of all members of the human population $(2011, \S 53)$.

\subsection{Substantive Criteria}

Most judgements on moral progress result from applying substantive, normative moral criteria. Substantive criteria are derived from what we call an evaluative base. A particular moral tradition, an overlapping consensus between diverse moral traditions or a normative theory that claims universal validity, such as a theory of human rights, can serve as an evaluative base. Thus, judgements on moral progress do not necessarily require a universalist evaluative base. Both the substance and the validity claim of an evaluative base depend on the aim of the evaluation and its intended forum.

Suppose that we want to prove to our fellow countrymen that the institutions of Dutch society and the moral behaviour of the Dutch have changed positively in the last century: the degree of correspondence between on the one hand Dutch moral beliefs, and on the other hand the behaviour of the Dutch and their institutions has increased. The most appropriate evaluative base is then the currently shared moral tradition of the Dutch. The audience or the forum of evaluation consists of the contemporary Dutch people, the members of the present Dutch society. However, if our audience are the citizens of the European Union, or of the United States of America we need an evaluative base than can be endorsed both by ourselves and our wider audience. In that case an overlapping consensus between moral traditions would be a more appropriate evaluative base, or a set of values and principles derived from an ethical theory. Some authors find that universal human rights are most fitting as an evaluative base (e.g. Buchanan 2013). Ruth Macklin's evaluative base consists of two universal principles: the principle of humaneness and that of humanity. They stem from two diverging ethical theories, utilitarian and Kantian theory: 
1) The principle of humaneness: One culture, society, or historical era exhibits a higher degree of moral progress than another if the first shows more sensitivity to (less tolerance of) the pain and suffering of human beings than does the second, as expressed in the laws, customs, institutions, and practices of the respective societies or eras. 2) The principle of humanity: One culture, society, or historical era exhibits a higher degree of moral progress than another if the first shows more recognition of the inherent dignity, the basic autonomy, or the intrinsic worth of human beings than does the second, as expressed in the laws, customs, institutions, and practices of the respective societies or eras (Macklin 1977, p. 371 f.)

Macklin's evaluative base may claim universal validity, but might not be universally endorsed, for example by adherents of non-Western moral traditions. This need not worry her, though, since her intended forum seems to be people in Western democracies. The same applies to Dale Jamieson's evaluative base, his 'index of moral progress': 'Whatever exactly moral progress consists in, it is plausible (for reasons I will explain later) to suppose that it involves at least the following: the abolition of war and slavery, the reduction of poverty and class privilege, the extension of liberty, the empowerment of marginalized groups, and respect for animals and nature' (Jamieson, p. 321). This index, he says, would be endorsed by a wide variety of ethical theories, but not by all. ${ }^{9}$ Jamieson concedes that it will be difficult to defend his index against the objection of ethnocentrism. ${ }^{10}$ An evaluative base such as those of Macklin and Jamieson might result in criteria that can be operationalised, but their applicability depends on whether they can be accepted by the intended audience of the evaluation.

\section{Gains and Losses: The Problem of Incommensurability}

In theory, a process of change may only bring either gains or losses, but in real life most processes of change produce a mixed bag of gains and losses. If the government of a country in Latin America decides to relocate a cultural group that lives in the Amazon rain forests because it wants to start mining for gold or drilling for oil, this may lead to an increase of welfare for society as a whole. Increase of welfare is generally considered as a gain, but there is also a loss. The loss consists of the disappearance of a unique way of life. How can we determine that this process of change is morally progressive? Here we are confronted with the problem of incommensurability. There are diverse interpretations of what that problem amounts to. In one interpretation, incommensurability means incomparability. A comparison takes place in relation to a value- the covering value. In the context of discussions on moral progress incommensurability implies that the state of affairs before the change is incomparable to the state of affairs after the change when there is no positive relation with respect to the covering value that holds between them: neither is better than or worse than the other nor are they equal (or on apar) (Chang 1997, p. 4) The two states of affairs might, e.g., be incomparable with respect to the value of freedom. Some authors argue that modernization has brought us both gains and losses in freedom. A second interpretation

\footnotetext{
9 'It would be rejected by some who believe that moral values are constituted by religious values, and that moral progress consists in the spread of Christianity or Buddhism, or increasing fidelity to the Koran or Tora' (p. 329). 10 'In the end I see no way to fully defend an index of moral progress short of defending the range of normative theories which find a place for the values it expresses. About all one can do in defending a normative theory, in my opinion, is to appeal to its intrinsic plausibility, and then demonstrate that it suffers from fewer and less severe infirmities and failures than alternative views' (Jamieson 2002b, p. 332).
} 
of incommensurability is nonsubstitutability. When a change causes one value to be sacrificed, this loss may sometimes be compensated for by a gain in another value. But when a loss in one value cannot be compensated for by a gain in another, the values are not substitutes for one another and are said to be incommensurable. Values are thought to be nonsubstitutable because some values have special 'status' (Anderson 1993) or are 'sacred' (Lukes 1997). The value of human life, for instance, is thought to have a special status so that its loss cannot be compensated for by economic gains. It is often said that modern society has brought us more individual freedom, both also less community and solidarity. If the loss of community and solidarity cannot be compensated by the gain in freedom, these values are incommensurable. A third interpretation of incommensurability is lack of a common unit of measurement. Two values, such as pleasure and fairness, are incommensurable if there is no cardinal scale of value according to which both can be measured.

Judgements on moral progress are thus complicated by the problem of incommensurability. This is clearly recognized by Philip Kitcher, although he does not use the term incommensurability:

So it might be suggested the fundamental notion is that of a transition that is progressive in certain respects; judgments of overall progress are made by adding the weights of the progressive respects and subtracting the weights of regressive respects. Sometimes the sum can be done, and we can talk confidently of a progressive (or a regressive) transition, but there will be occasions on which no common scale for comparison can be found, when no determinate weights can be assigned, and no overall judgment can be reached (Kitcher 2011 p. 2111 f.).

Michelle Moody-Adams also admits that progress in one domain may go along with regress in another domain: 'Changes that are reasonably deemed to constitute moral progress occur locally, in reasonably circumscribed domains of concern’ (1999, p. 169). 'But since moral progress is always local, we need not establish that beliefs and practices are all headed in a single direction to identify particular instances of moral progress ' ( $\mathrm{p}$. 170). The problem of incommensurability does not worry Moody-Adams much because she is more interested in how we can realise local and partial-moral progress here and now in specific domains - than in a more comprehensive domain-transcending evaluation of the moral states of affairs in, say, two historical periods of a society. On local moral progress, Kitcher comes a similar conclusion as Moody-Adams:

While the conception of ethical progress so far elaborated cannot pronounce on questions about some large historical or prehistorical trends ('Was the shift from Primitive life to Civilized life progressive?'), that does not leave us uncertain about how to go on from where we are (2011, p. 244).

\section{The Contributions to This Issue}

Our overview and analysis of recent literature on moral progress makes it easier to situate the papers in this issue within the discussion on moral progress, and to determine what they contribute to that discussion. Most of the papers are dedicated to conceptual and theoretical questions regarding moral progress, in two of them - the papers by Dale Jamieson and Michelle Moody-Adams - a practical interest is leading: how to make partial and local moral progress happen? 
In the paragraph on epistemic criteria we referred to the debate on the meta-ethical presuppositions of a belief in moral progress. As we have seen, some authors find that one cannot talk about moral progress without being committed to moral realism. None of the contributors to this issue defends this thesis. ${ }^{11}$ Caroline T. Arruda suggests in her paper that another metaethical theory, meta-ethical constructivism, has also a pressing need to explain moral progress. She states that for the meta-ethical constructivist moral progress ought also mean that agents come to be - or could come to be - motivated to act in light of the right kind of moral judgments: moral progress must be explained as a form of moral improvement, or agents aspiring to be better sorts of moral agents. After discussing various forms of constructivism, she concludes by showing that only constructivism as a view about practical reason can fully account for moral progress qua the opportunity for moral improvement.

In our overview, we only touched upon what evolutionary accounts of the origin of morality can tell us about moral progress. Julia Hermann's paper examines in more detail what evolutionary explanations are able to tell us about the possibility of moral progress and the ways in which such progress can be achieved. She argues that evolutionary explanations can inform moral education and other forms of moral enhancement, and that increased evolutionary knowledge figures among the changes in the circumstances of morality that can lead to moral progress. Evolutionary explanations can show us certain limits to the possibility for humans of progressing morally as well as certain enabling conditions. Hermann thinks that both aspects - enhancement and changes in the circumstances - are equally important for the achievement of moral progress. In their paper, Markus Christen, Darcia Narvaez and Eveline Gutzwiller present two evolutionary views on moral progress: a biological and a cultural one. The biological view sees human morality as an advanced adaptation to enable the uniquely derived lifestyle of human foragers, which requires generosity and sharing due to extreme mutual interdependence for survival, thriving and dispersal. Compared to such a small-band hunter-gatherer (SBHG) baseline, the current mode of human existence involves a considerable degree of organized emotional and psychological violence to humans, and destructive behaviour towards other-than-humans, which can be interpreted as an expression of moral decline. The cultural view relates moral progress to dealing with an increasing diversity of temptations and possible wrongdoings in a human social world whose complexity accumulates in time. In their contribution, Christen, Narvaez, and Gutzwiller describe these two different views of moral progress, discuss how they interact, how this interaction impacts the standards by which we measure moral progress, and also provide justifications for re-aligning biological and cultural moral progress. ${ }^{12}$

Problems with defining moral progress are central to Jeremy Evans' paper. He states that behind the consensus about the outlawing of slavery, the beginning of women's suffrage, or the defeat of Nazism as paradigmatic examples of moral progress in human history lies a deep division about the nature of moral progress more generally, which is a consequence of the foundational differences among and within normative traditions regarding the nature and scope of the 'moral' in moral progress. Evans proposes that philosophers might nonetheless converge on a working definition of moral progress by identifying a proxy property that reliably tracks moral progress, but which does not purport to be coextensive with the philosophically-relevant property. The aim of his paper is to identify this proxy property with emerging empirical

\footnotetext{
${ }^{11}$ In his contribution, Dale Jamieson repeats his earlier criticism (Jamieson 2002a, b) on the thesis.

12 Dale Jamieson also gives a sketch of an evolutionary view on the origins of morality in his contribution.
} 
measures of population welfare, and to show why this indicator of moral progress can garner overlapping consensus from a variety of normative traditions.

Reasoning, part of the cognitive component of morality, is an important element of moral practice. According to one conception moral progress consists of improving moral reasoning, meaning that moral judgements come closer to moral truth. Research suggests, however, says Jesse S. Summers in his paper, that the explicit reasoning we offer to ourselves and to others is often rationalization: we tell a post hoc story to justify our actions. This is troubling for views of moral progress according to which moral progress proceeds from our engagement with our own and others' reasons. Summers considers an account of rationalization to make clear that rationalization, unlike simple lying, can be sincere. Because it can be sincere, and because we also have a desire to be consistent with ourselves, Summers argues that rationalization sets us up for becoming better people over time, and that a similar case can be made to explain how moral progress among groups of people can proceed via rationalization. One of the widespread deficits in moral reasoning is that it is affected by the reasoners' ignorance. Since moral reasoning has at least some influence on moral behaviour, ignorance is usually regarded as an important obstacle to progress in moral practices. Jan Willem Wieland presents in his paper an analysis of wilful ignorance. In his concept of wilful ignorance, rationalization is one of its symptoms. What obstructs moral progress, according to Wieland, is wilful ignorance motivated by what he calls 'backward-looking' and 'forward-looking self-interest'. We do not want to consider whether our practices are wrong, first because we have engaged in them for too long, and realizing this will seriously affect the image we have of ourselves. Second, we do not want to consider it, because it is in our interests if we stay ignorant: slaveholders want to keep their cheap workers, and consumers want to keep on buying cheap clothes.

It is common to distinguish (collective) moral progress from (individual) moral development, but this distinction is artificial since moral development could also be seen as a kind of moral progress. Since Jean Piaget, psychologists see moral development as a process consisting of different stages. Before him the father of sociology, August Comte, thought that human society goes through various developmental stages. Anders Schinkel and Doret J. de Ruyter analyse the concept of moral progress to shed light on the psychology of moral development and vice versa; these analyses are found to be mutually supportive. They suggest that moral progress should be conceived of as development that is evaluated positively on the basis of relatively stable moral criteria that are the fruit and the subject of an ongoing conversation; moral progress does not imply the idea of an end-state; individual moral progress is best conceived of as the development of various components of moral functioning and their robust integration into a person's identity; both children and adults can progress morallyeven though we would probably not speak in terms of progress in the case of children - but adults' moral progress is both more hard-won and to a greater extent a personal project rather than a collective effort.

Moral progress is a process of change. Joining Dale Jamieson, we stated that a change can only be called progressive when a subsequent state is overall better than a preceding one. Claims about moral progress are what Toni Rønnow-Rasmussen in his paper calls comparative 'betterness claims.' He makes a distinction between intra- and inter-comparisons. Intra-comparisons are comparisons between two (historical, developmental) stages of the same entity - a person, or a society. Inter-comparisons are comparisons between two different entities. Society x can be said to have made more moral progress than society y in the same time span. Jamieson's definition of moral progress clearly assumes than moral progress claims are intra-comparisons. Rønnow- 
Rasmussen does not make substantive statements, for example about what makes a subsequent state better than a preceding one; his analysis of betterness-claims is purely formal. In the section which goes into certain logical features of betterness in light of recent work in value theory, Rønnow-Rasmussen also discusses incommensurability and incomparability. If we say that a student has made considerable progress in his papers, we assume that this is caused by his own efforts. If it turns out that somebody else has written his papers, we would certainly withdraw that statement. Rønnow-Rasmussen calls this the 'agency-requirement' for moral progress. Although it seems obvious that this requirement applies when we speak of moral progress made by persons, he argues that also persons can be said to have made moral progress without them having been actively involved in the process of change.

The leading interest in the last two papers, by Michelle Moody-Adams and Dale Jamieson, is in how to make a society a morally better place. The idea of moral progress, according to Moody-Adams in her paper, is a necessary presupposition of action for beings like us. We must believe that moral progress is possible and that it might have been realized in human experience if we are to be confident that continued human action can have any morally constructive point. There is, Moody-Adams argues, certainly a place for philosophy, including normative theory, in helping to shape morally concerned social criticism and in encouraging morally engaged political struggle, but moral progress depends primarily on the efforts of morally engaged agents. Morally progressive changes are the work of effective social movements which often rely on innovative language to expand conceptual space for constructive debate about moral progress. ${ }^{13}$ Moral progress also often depends on expanding perceptual space - dislodging prejudices and habits of belief that limit our ability to take a novel view of the world, our place in it, and our relationships to others, as might be required by new moral interpretations. Discursive reason-giving and argument are often ineffective in these contexts, and sometimes, Moody-Adams says, we must rely instead on the arresting, disarming, and perceptually disruptive power of creative expression to produce morally necessary transformations in how human beings perceive the world, and their place in it. In the final contribution to this issue, Dale Jamieson also turns to history for lessons that might help in realising the kind of moral progress that is needed for combating climate change. History can show us how moral progress actually occurs. Jamieson begins by restating a conception of moral progress set out in previous publications (2002a,b), the 'Naïve Conception', and explains how it comports with various normative and meta-ethical views. He goes on to develop an index of moral progress and to show how judgments about moral progress can be made. The historical example of moral progress he discusses is the British abolition of the Atlantic slave trade. Perhaps the most important lesson climate campaigners can learn from the movement to abolish the Atlantic slave trade, Jamieson argues, is that for people to support moral change in a world in which there is a rupture in space, time, or scale between a cause and a harm, they must somehow be reconnected in their consciousness. Abolitionism succeeded because it closed the circuit between the near and the far, the proximate and the distal. After British Parliament rejected an abolition bill in 1791, the abolitionists launched the 'blood sugar' campaign - forcefully linking sugar consumption in England to the suffering of slaves on the other side of the Atlantic - which resulted in at least 300,000 people boycotting Britain's largest import. The fundamental challenge faced by fossil fuel abolitionists is to connect the harms of climate change with the use of fossil fuels.

\footnotetext{
${ }^{13}$ A similar view on the role of social movements in inducing progressive moral change can be found in Elisabeth Anderson (2014).
} 


\section{Taking Stock}

We started this introduction with two questions: 1) Is the world today a morally better place to live in than, say, a century ago? and 2) How can we make the world a morally better place? What has become clear is that both questions as such cannot be answered because they are too abstract and too general. We need first to choose a specific historical period and a specific part of the world; for example, 'Are the Netherlands of the 21 st century a morally better place to live in than the Netherlands in the 16th century?' Second, we need to decide on which component (s) of the morality system we want to focus our judgement: beliefs, motivations, behaviour, or institutions. Third, we need to choose criteria that are relevant to the chosen focus.

Two problems surround judgements about the morally progressive nature of changes, even if we concentrate on changes in a specific historical period in a specific society or nation. The first problem concerns the evaluative base - at least if we want to use substantive criteria in our evaluation. It is almost impossible to find an evaluative base that is universally endorsable. Judgements on moral progress are usually not addressed to a global audience, but to a specific - actual or virtual - audience that shares the evaluator's moral outlook. Most contemporary Dutchmen will agree that the Netherlands since the 16th century made moral progress. It is doubtful whether Dutchmen from the 16th century would also agree. The second problem is that of incommensurability. Kitcher and Moody-Adams find that it is almost impossible to justify (retrospective) judgements on (comprehensive) moral progress (in specific historical periods in specific societies) because of problems inherent to weighing gains of changes against losses. We cannot, and do not have to, choose between the modern Dutch way of life and the way of life in the 16th century. The latter way of life is no longer available to us. Assume that we find the 16th century Dutch society morally better than the modern way of life. Morality is not a module of social life that can be transplanted into another way of life. Moral changes are induced by, and go along with, economic and technological changes. We cannot return to the moral life of the 16th century without giving up the advantages, the comfort, safety, and welfare of 21 th century Netherlands.

We hope that this special issue will result in, at least, some epistemic progress in thinking about moral progress.

\section{References}

Anderson E (1993) Value in ethics and economics. Harvard UP, Cambridge

Anderson E (2014) Social Movements, Experiments in Living, and Moral Progress: Case Studies from Britain's Abolition of Slavery. The Lindley Lecture, University of Kansas, February 11

Boyd R (1988) How to be a moral realist. In: Sayre-McCord G (ed) Essays on moral realism. Cornell UP, Ithaca, pp $187-228$

Buchanan A (2013) Moral progress and human rights In: C Holder \& D Reidy (eds) Human Rights: The Hard Questions. Cambridge UP, Cambridge, pp. 399-418

Chang R (1997) Introduction. In: Chang R (ed) Incommensurability, incomparability, and practical reason. Harvard UP, Cambridge, pp 1-34

Comte A (1830-1842) Cours de philosophie positive. English translation \& condensation: The Positive Philosophy of August Comte, by Harriet Martineau (1853)

Crozier JB (1898) Civilization and Progress 4th ed. Longman, Greens and Co, London \& New York

Godlovitch S (1998) Morally we roll along: (optimistic) reflections on moral progress. J Appl Philos 15(3):271-286

Huemer M (2016) A liberal realist answer to debunking skeptics: the empirical case for realism. Philos Stud 173: 1983-2010

Jamieson D (2002a) Morality's progress: essays on humans, other animals, and the rest of nature. Oxford University Press, Oxford 
Jamieson D (2002b) Is there progress in morality? Utilitas 14:318-338

Kant I (2002) Groundwork for the Metaphysics of Morals, A.W. Wood (ed \& transl). Yale UP, New Haven

Kitcher P (2011) The ethical project. Harvard UP, Cambridge

Lecky WEH (1809) History of European morals. D. Appleton \& Co, New York

Macklin R (1977) Moral progress. Ethics 87(4):370-382

Lukes S (1997) Comparing the incomparable. Trade-offs and sacrifices. In: Chang R (ed) Incommensurability, incomparability, and practical reason. Harvard UP, Cambridge, pp 184-195

Moody-Adams M (1999) The idea of moral progress. Metaphilosophy 30:168-185

Rest J (1986) Moral development: advances in research and theory. Praeger, New York

Singer P (1981) The expanding circle: ethics and sociobiology. Farrar, Straus \& Giroux, New York

Warnock GJ (1971) The object of morality. Methuen, London

Wilson C (2010) Moral progress without moral realism. Philos Pap: 97-116 